

\title{
Anxiety and Urban Stress for Parking Spots
}

\author{
Bujar Bajçinovci ${ }^{1}$, Mejreme Bajçinovci ${ }^{2 *}$ \\ ${ }^{1}$ University of Prishtina, Faculty of Civil Engineering and Architecture, Kosovo. \\ ${ }^{2}$ National Institute of Public Health, Prishtina, Kosovo. \\ Email:mirebaj@yahoo.com,bujar.bajcinovci@uni-pr.edu
}

\begin{abstract}
:
The lack of a sustainable urban mobility plan for the city of Pristina and its linkage to spatial plans in the future will bring serious problems for the city, which will have a negative impact on the quality of life. Lack of a serious and professional approach to sustainable city planning, uncontrolled expansion and without predetermined criteria, social cohesion and services have brought the city to a critical point of development. It is clear that the factual situation of parking lots in Pristina is problematic. The need for parking spaces and public parking garages in Prishtina are very immediate. There is no parking plan where there are legal, private parking, illegal parking lots. Therefore, it is important to provide data on the basis of which will be the best solution for parking regulation and categorization. Moreover, there is a solution, but we have to pay! Urbanites, both private and commercial, will have to rent out a variety of parking spaces through the urban zone from commercial vehicle parking operators.
\end{abstract}

Key words: Prishtina, Parking Spots, Urban Stress, Spatial Organization.

\section{INTRODUCTION}

The lack of a sustainable urban mobility plan for the city of Pristina and its linkage to spatial plans in the future will bring serious problems for the city, which will have a negative impact on the quality of life. Lack of a serious and professional approach to sustainable city planning, uncontrolled expansion and without predetermined criteria, non-compliance with the planning hierarchy, lack of synergy between areas of housing blocks, approval of the number of neighborhoods without any study on access, space, environment, social cohesion and services have brought the city to a critical point of development. With the enormous number of gravitated vehicles and the lack of parking spaces and facilities, almost every neighborhood in Pristina is in the mental state of protecting the parking space. The scenario for the active city is good because with Prishtina's dynamics it needs to be channeled towards the city for its urbanites, with the 
promotion of active movement, cycling, sustainable urban transport, parking and a sustainable vehicle movement network [1]. Cities are complex organisms, it can be conceptually considered that cities are locally and regionally specific [2], but, some universal features are the same for every city or urban space. Free parking space! This is the most elementary urban need nowadays! Furthermore, there is a lot of stress finding the free parking lot, especially when we have to park after a hard Labor Day in the vicinity of our residential area. "Stress has been defined as any external (to the body) stimulus that threatens homeostasis, the normal equilibrium of body functions. High levels of stress lead to disease and even death because they compromise homeostatic mechanisms" [3]. Actually, there are increasing number of incidents as a result for finding the free parking space, most of the time the Kosovo Police has had to intervene to stop fighting's, while the participants suffered light bodily injuries, for which medical treatment was offered. Lately, the situation has become more drastic when the police reports that in Suhareka town three people after a dispute over a parking lot for vehicles, start fighting. One of the suspects has also used a firearm, suspected of having been injured by a casual citizen. The victim received urgent medical treatment. Stress situations for finding the free parking spot goes even worse when two officials of the Municipality beat up for parking space, even the parking lots for the municipality workers are dedicated! Similar situations, where a woman and her husband say they were attacked by a neighbor for taking the parking spot his been waiting for. "In January 2016, the AA polled 25,000 drivers, with the results suggesting Londoners have the highest parking-related stress levels. Of all the capital's drivers surveyed, 36 per cent said they get anxious about parking. Almost a quarter said they postponed or abandoned journeys altogether because they panicked, they wouldn't find an available space near where they live" [4]. The Automobile Association Developments Limited (GB) with Driver Poll surveys in September 2015, there were 24,739 responses to the motoring panel survey between 14 and 22 September 2015, "one third of respondents (32\%) agree that parking availability on their street is so bad they worry about finding a space when they return. When driving to work, just over one third of respondents worry about being able to park (36\%), or avoid using their car at lunchtime for fear of losing their parking space (37\%)" [5]. Also, with Driver Poll surveys in January 2016, there were 26,463 responses to the January 2016 motoring panel survey between 18 and 25 January 2016. "A large proportion of AA Attribution License http://creativecommons.org/licenses/by/4.0/, which permits unrestricted use, provided the original author and source are credited. 
panel members $(91 \%)$ agree that car parking spaces are often too small compared to the size of modern cars. Just under three quarters (74\%) often worry about the possibility of their car getting damaged while it's parked and a further half (51\%) generally try and park in the quietest part of the car park to reduce risk of damage to their car. Only half (48\%) of respondents read the terms and conditions of parking very carefully when parking in an unfamiliar car park" [5].

\section{MATERIALS and METHODS}

The study presented in this paper investigated the Prishtina City, focusing on free parking spot issues, and traffic problems. The research methods consist of empirical observation, and literature review. In order to receive a clearer data and information's, research is made within Centre zone area, focusing on free parking spots and possible anxiety for finding one on the city of Prishtina, environmental pollution, and humongous traffic rhythm with urban fulmination for parking spaces. Case study were investigated through literature review, urban city documentations and drawings. The data collected include maps, composition of urban structure, and attributes of space, dimensions of location and traffic activities. The additional data for this paper is based on the analysis of the Municipality of Prishtina archives.

Table 1. Vehicle registration of 2014-2017- Kosovo [6].

\begin{tabular}{l|lllll} 
& 2014 & 2015 & 2016 & 2017 & Grow 2014-2017 \\
\hline Vehicles & 236145 & 281847 & 260291 & 273862 & $+8 \%$ \\
\hline Trans vehicle, 3.5 and over 3.5 Mt & 15769 & 18330 & 17963 & 2735 & $-73 \%$ \\
\hline Trans truck, under 3.5 Mt & 26949 & 30846 & 31285 & 288 & $-935 \%$ \\
\hline Minibus & 3161 & 3212 & 2841 & 1690 & $-47 \%$ \\
\hline Buses & 1697 & 2124 & 1916 & 523 & $-60 \%$ \\
\hline Motorcycles & 1540 & 1849 & 1790 & 2535 & $+64 \%$ \\
\hline Tractors & 1036 & 941 & 613 & 1949 & $+88 \%$ \\
\hline Trailer under 3.5 Mt & 250 & 286 & 288 & 32299 & $+1290 \%$ \\
\hline Trailer 3.5 and above 3.5 Mt & 2281 & 2707 & 2628 & 18559 & $+813 \%$ \\
\hline Total & 288828 & 342142 & 319615 & 334440 & $+86 \%$
\end{tabular}


According to the data presented in Table 1, it is clear that the number of registered vehicles is increasing every year. Lack of additional data such as the year of production, combustion model, producer, origin of the state, does not allow us to find out why this growth trend is happening. Also, it is not clearly known what is the role of Law no. 05 / L-132 for vehicles published on 11.05.2017 no: 15/2017 where it cites the registration of vehicles older than 10 years [1].

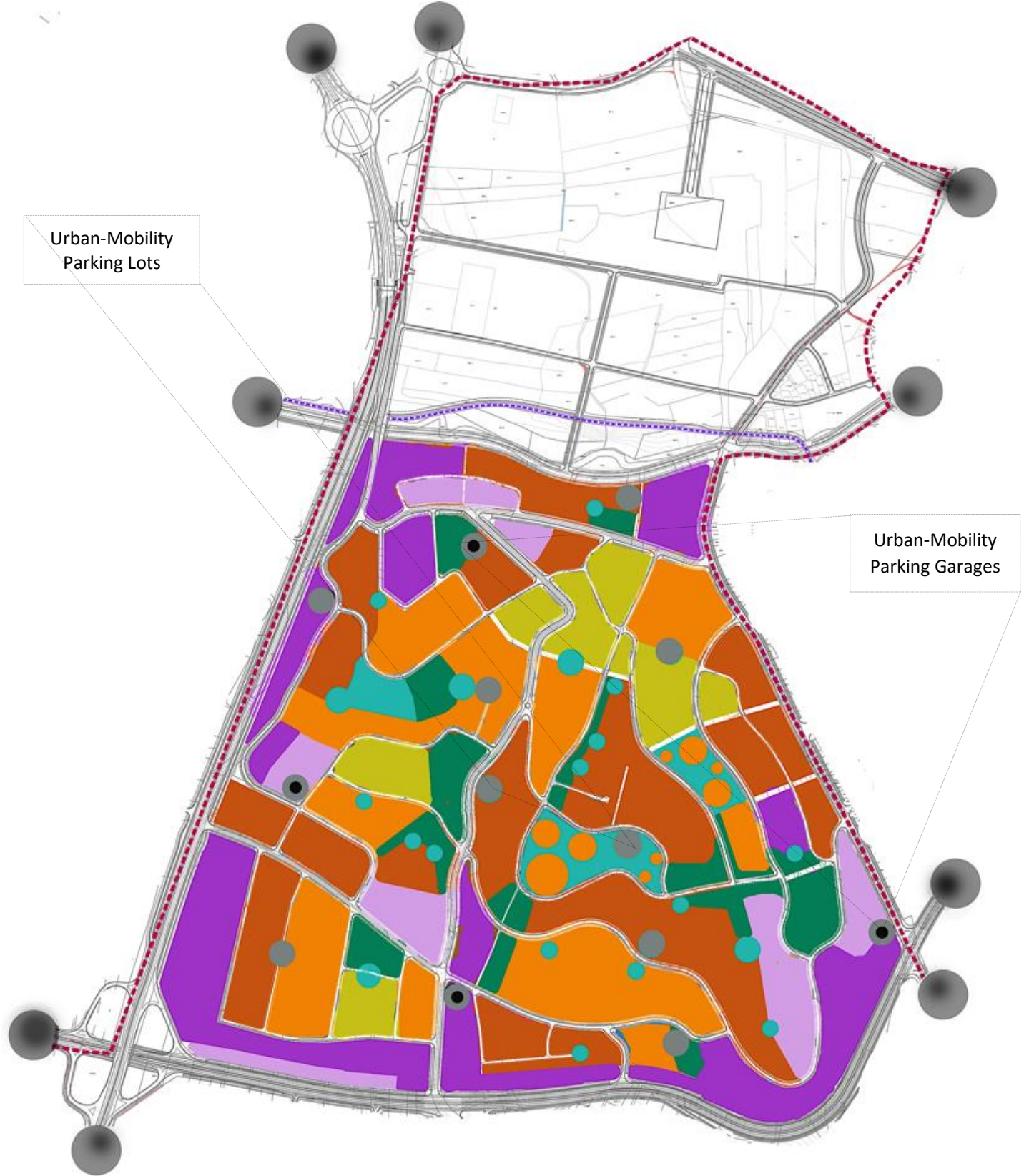

Figure 1. Urban zone with preferred parking garages lots. [M. Prishtina; Bajçinovci, B. 2019] 


\section{DISCUSSION}

The need for parking spaces and public parking garages in Prishtina are very immediate, moreover, the sustainable urban and architectural design is facing major challenges as a result of many contemporary factors: heavy traffic, air pollution, life style, and economy. On the other hand, Kosovo is also participating in global trends, a process by which regional economies, societies and cultures are integrated through a global network.

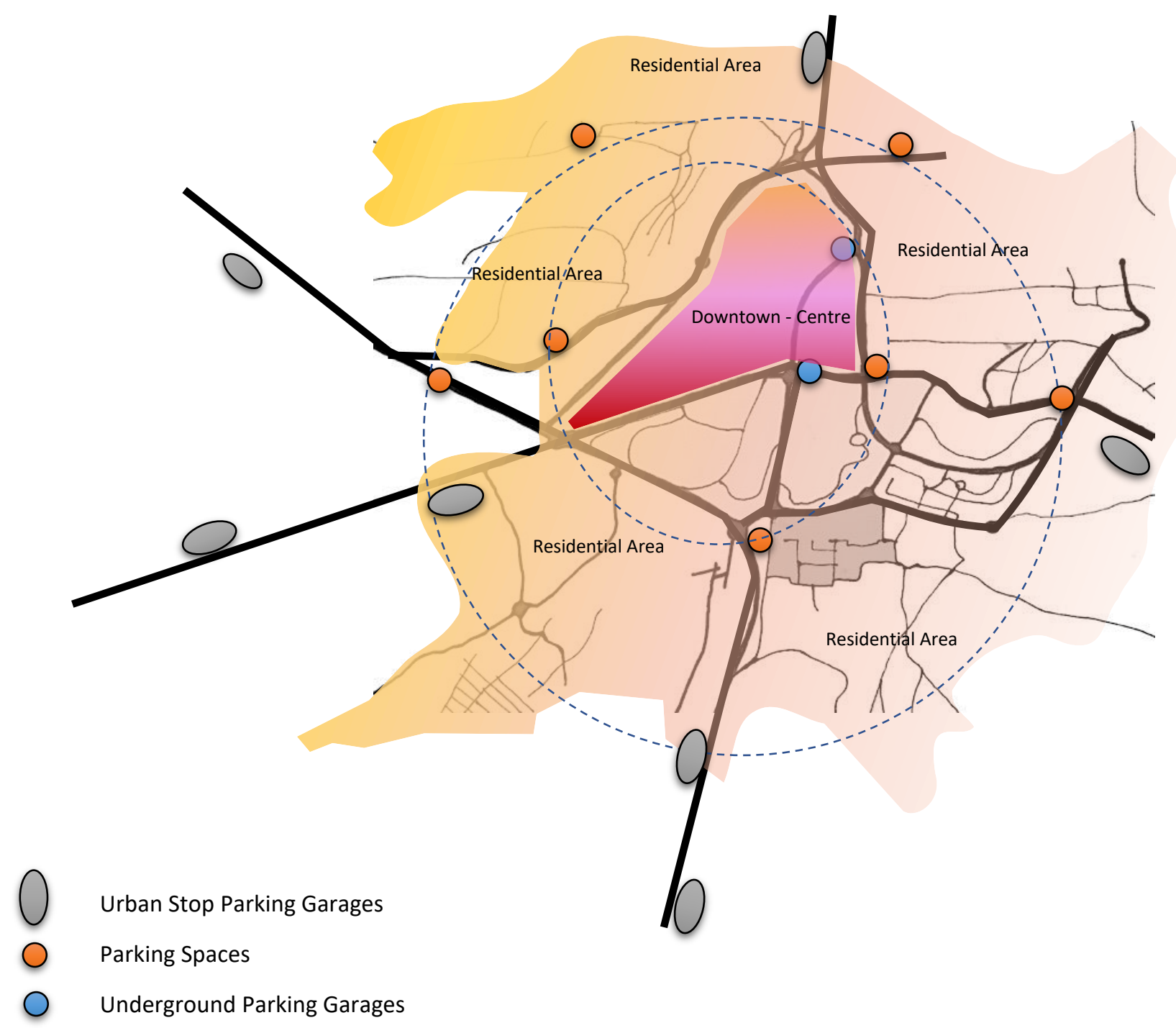

Figure 2. Proposal of Parking Spaces, and Underground Parking Garages, Prishtina [1]. 
On the other hand, Kosovo is also participating in global trends, a process by which regional economies, societies and cultures are integrated through a global network of political ideas, communication, transport and market sharing. According to the data from the Kosovo police, "Pristina with the current infrastructure cannot be withstood a flow of 120,000 vehicles within 24 hours, especially in the hours when the population goes and comes from work, school and other needs such as hospitals, various institutions" [2,7].

"I am tempted to dwell on the importance of the parking lot. I enjoy it as an austere but beautiful and exciting aspect of the landscape. I find it easy to compare it with such traditional vernacular spaces as the common: both are undifferentiated in form, empty ... But on another level, the parking lot symbolizes a closer, more immediate relationship between various elements in our society: consumer and producer, public and private, the street and the dwelling" [8,9].

Furthermore, "While ordinary places, such as parking lots, may not be aesthetically pleasing to all, they do serve the purpose they are intended to fulfill, and sometimes a lot more. In the American context, parking lots may be the most common regularly used public outdoor open space... Parking lots are one of the few places that cars and pedestrians share and coexist in" [9].

It is clear that the use of urban traffic is indispensable. Obstacles in the urban transport, wild competition by illegal car operators significantly impede the sustainable development of urban public transport. However, the functionalization of urban public transport is economically viable with these capacities operating in Prishtina, whereas in the days of the weekend it is clear from the visual state and from the data that the number of usages is significantly lower in both directions. The factual situation counts for the mobility have continued with the parking process. It is clear that the factual situation of parking lots in Pristina is problematic. There is no parking plan where there are legal, private parking, illegal parking lots. Some anti-dumping measures have been carried out in the past mainly by using robust measures such as the placement of metal bars.

Therefore, it is important to provide data on the basis of which will be the best solution for parking regulation and categorization. Surveys were conducted in 10 areas of the city of Prishtina. For this issue are engaged students who have identified the number of parking lots and occupancy, their 
occupation interval over the day. The first results show that over $50 \%$ of the use of the parking lots are occupied of the daytime period, which means that they are used by the residents of the area, hence, occupied as well from employees within the zone where the count was performed.

Usually, there are hot and cold parking spots, "Looking for parking takes in average 15 to 20 minutes in the busiest cities. Car parking keeps us from what's next in our lives. Meetings, friends, family, shopping. We invest a lot of time in parking, and the reward is to simply go doing what you were supposed to do from the very beginning" [10].

\section{CONCLUSION}

There is a conceptual urban strategy to offer a variety of public parking spaces and parking garages, also there is need that those type of buildings blend in within an urban composition with a cultivated vegetation. Moreover, there is a solution, but we have to pay! Urbanites, both private and commercial, will have to Rent Out a variety of parking spaces through the urban zone, including driveways, private off-street parking spaces, lock-up garages and spaces from commercial vehicle parking operators [11].

\section{REFERENCES}

[1] Bajçinovci, B., Aliu, V., Dinarama, R. (2019). Humongous Traffic Rhythm: Urbane Fulmination for Parking Spaces in Prishtina. Unpublished Research.

[2] Bajçinovci, B., Jerliu, F. (2016). Challenges of Architectural Design in relation to Environment and Air Pollution. A Case study: Prishtina's first public parking garage. Journal of Science, Humanities and Arts. Volume 3, Is. 7. DOI: 10.17160/josha.3.7.254

[3] Eberhard, P. J. (2009). Brain landscape: the coexistence of neuroscience and architecture. Oxford University Press, Inc. New York. USA. ISBN: 978-0-19-533172-1

[4] Wimble-Groves, J. (2017). www.huffingtonpost.co.uk/jo-wimblegroves/car-park-anxiety-itsa-re_b_15267800.html, $\quad$ https://www.thisismoney.co.uk/money/cars/article3401389/Drivers-avoid-using-car-don-t-lose-spot-street.html [Accessed: 4 January 2019].

[5] AA. Automobile Association Developments Limited (GB). Driver Poll surveys 2015, 2016. https://www.theaa.com, [Accessed: 4 January 2019]. 
[6] SAK, 2018. http://ask.rks-gov.net/en/kosovo-agency-of-statistics. <http://askdata.rksgov.net/PXWeb/pxweb/sq/askdata/askdata Transport/tr05.px/? rxid=a68d80f4-e84a-44b9beb1-661fa7c95768> [Accessed: 4 January 2019].

[7] Haziraj, A. F., Media officer - Regional Police Directorate in Pristina, 2013. http://www.arkivalajmeve.com/240-mije-vetura-ne-ldquorksrdquo-100-mije-vetem-nePrishtine.1047418855/ > [Accessed: 22 August 2016].

[8] Jackson, J. B. (2000). Landscape in Sight: Looking at America. Yale University Press; Revised edition. ISBN: 978-0300080742

[9] Ben-Joseph, Eran. (2012). ReThinking a lot: the design and culture of parking. The MIT Press, Cambridge, Massachusetts London, England. ISBN 978-0-262-01733-6

[10] Witrafi. (2017). How To Get To Stress Free Parking. http://witrafi.com/stress-free-parking/ [Accessed: 3 January 2019].

[11] This is Money. (2016). Drivers avoid using car so they don't lose their spot in the street. https://www.thisismoney.co.uk/money/cars/article-3401389/Drivers-avoid-using-car-don-tlose-spot-street.html, [Accessed: 4 January 2019].

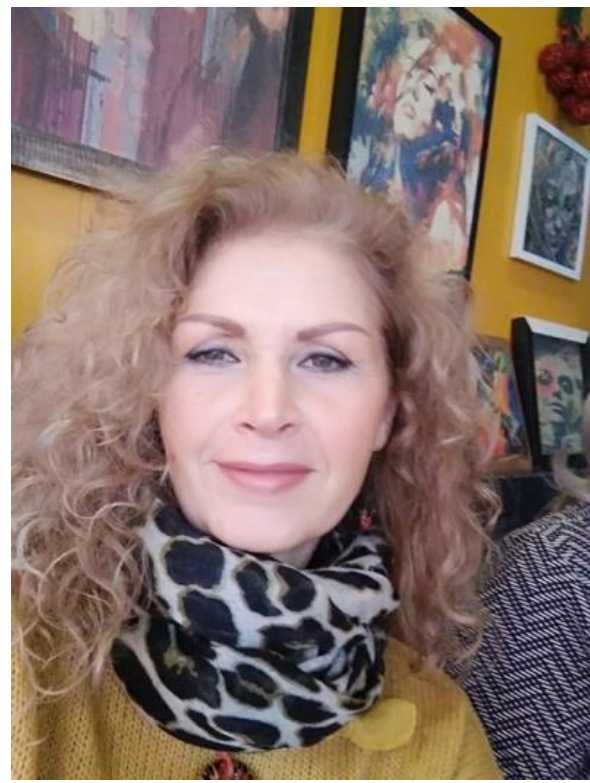

Mejreme Bajçinovci Medical Doctor, Public Health Specialist, she was born in Prishtina. Currently works at the National Public Health Institute in Prishtina, Kosovo. Main activities and responsibilities: Management, organization, planning, programming, promotion, supervision on Public Health. From 1999-2000 she was Public Health Supervisor creating Health materials and messages (mass medias) IRC (International Rescue Comity), and Health Promotion. From 2000-2001 she was National trainer on Health Promotion, organization, programming, training, supervision at WHO (World Health Organization) Office in Kosovo, also on Health Promotion. From 1994-1999 she was MD, at the NGO Mother Teresa in Prishtina. She is an author of 2 scientific publications. She attended more than 32 international conferences, also she is certified Public Health Specialist at the Chamber of MD in Kosovo. E-mail: mirebaj@yahoo.com 